\title{
EFFICACY AND SAFETY OF RISPERIDONE ORAL SOLUTION IN AGITATION ASSOCIATED WITH DEMENTIA IN THE ELDERLY
}

\author{
Jerson Laks ${ }^{1}$, Eliasz Engelhardt ${ }^{1}$, Valeska Marinho ${ }^{1}$, Marcia Rozenthal ${ }^{1}$, \\ Fernando de Castro e Souza ${ }^{1}$, Josué Bacaltchuk ${ }^{2}$, Alberto Stoppe Jr. ${ }^{3}$, \\ R.C.R. Ferreira ${ }^{3}$, Cassio Bottino ${ }^{3}$, M ônica Scalco ${ }^{3}$
}

\begin{abstract}
Background: Behavioral and psychological symptoms in dementia (BPSD) contribute to caregiver burden and institutionalization of elderly. Neuroleptics are prescribed to control agitation. Side effects of typical neuroleptics are harmful, making atypical neuroleptics an indication. Objectives: To evaluate efficacy and tolerability of risperidone oral solution (ROS) given once daily to demented elderly outpatients with BPSD (agitation). Method: Patients $(n=26), 76.35 \pm 8.63$ years, Diagnostic and Statistical Manual of Mental Disorders $4^{\text {th }}$ ed. (DSM-IV) criteria for dementia. RSO was given, starting dose of $0.25 \mathrm{mg}$ and increments of $0.25 \mathrm{mg}$ every week. Mini-Mental State Examination (MMSE) assessed cognitive status, Behavioral and Emotional Activities Manifested in Dementia (BEAM-D) and Clinical Global Impression (CGI) measured BPSD, Extrapiramidal Symptom Rating Scale (ESRS) evaluated extrapyramidal symptoms. Cardiovascular side effects were evaluated clinically. Results: There was a $26 \%$ reduction in agitation and no cardiovascular side effects in the range from 1.0 to $1.25 \mathrm{mg}$. Side effects were more prevalent above $2.5 \mathrm{mg}$. Conclusion: Risperidone oral solution improved agitation with good tolerability from 0.5 to $1.25 \mathrm{mg}$. A single dose with increments of $0.25 \mathrm{mg}$ may be more acceptable to patients and caregivers.
\end{abstract}

KEY WORDS: risperidone, dementia, BPSD, elderly.

\section{Eficácia e segurança de risperidona solução oral na agitação associada a demência em idosos}

RESUMO - Fundamentos: Sintomas psicológicos e do comportamento nas demências (BPSD) contribuem para a sobrecarga dos cuidadores e institucionalização dos idosos. Neurolépticos são prescritos para agitação. Efeitos colaterais dos típicos são prejudiciais, sendo os atípicos indicáveis. Objetivo: Avaliar eficácia e tolerabilidade da risperidona solução oral (RSO), dose única diária, em idosos demenciados ambulatoriais com BPSD (agitação). M étodo: Pacientes ( $n=26), 76,35 \pm 8,63$ anos, critérios do Manual Diagnóstico e Estatístico de Transtornos Mentais 4.ed. (DSM-IV) para demência. RSO administrada, com dose inicial de 0,25 mg e incrementos de $0,25 \mathrm{mg}$ toda semana. Foram utilizados mini-mental (MEEM) para estado cognitivo, behavioral and emotional activities manifested in dementia (BEAM-D) e clinical and global impression (CGI) para BPSD, extrapyramidal symptom rating scale (ESRS) para sintomas extrapiramidais. Efeitos colaterais cardiovasculares foram avaliados clinicamente. Resultados: Houve redução de $26 \%$ na agitação, sem efeitos colaterais cardiovasculares, numa faixa de 1,0 a 1,25 mg. Efeitos colaterais foram mais prevalentes acima de 2,5 mg. Conclusão: Risperidona melhorou agitação com boa tolerabilidade entre 0,5 e 1,25 mg. Dose única diária e aumentos de $0,25 \mathrm{mg}$ podem ser mais aceitáveis para pacientes e cuidadores.

PALAVRAS-CHAVE: risperidona, demência, BPSD, idosos.

Non-cognitive behavioral disorders are prominent features of dementia ${ }^{1}$ and often lead to nursing home placement, besides the patient's distress, caregivers' burden and serious medical complications ${ }^{2-4}$. Such disorders have been reported as behavioral and psychological symptoms of dementia (BPSD), being present in up to $90 \%$ of demented patients studied $^{1,5,6}$. The majority of studies published on the sub- ject deal with case series and/or severely institutionalized demented patients.

The most conventional pharmacological treatment for these problems is the use of neuroleptics ${ }^{3,7,8}$. However, the majority of studies are open label trials with no placebo control, making it difficult to ascertain the efficacy and side-effect profiles of these drugs. This is mainly due to difficulties in defining

${ }^{1}$ Psychogeriatric Unit/Institute of Psychiatry of Federal University of Rio de Janeiro (UFRJ), Rio de Janeiro RJ, Brazil; ${ }^{2}$ Federal University of São Paulo (UNIFESP/EPM), São Paulo SP, Brazil; ${ }^{3}$ Proter/Institute of Psychiatry University of São Paulo Hospital (HC-USP) São Paulo SP, Brazil. Supported by Janssen-Cilag.

Received 18 December 2000, received in final form 3 August 2001. Accepted 7 August 2001.

Dr. Jerson Laks - Av. Nossa Senhora Copacabana 749/1101 - 20250-000 Rio de Janeiro RJ - Brasil. 
agitation, a broad assembly of syndromes that range from delusions and anxiety manifestations to wandering and so on ${ }^{8,9}$. Nine double-blind, placebo controlled trials evaluated the use of typical neuroleptics in dementia. Although haloperidol and thioridazine have been shown to be superior to placebo in treating psychotic symptoms in dementia, a considerable degree of extrapyramidal symptoms have also been described $^{8}$. Hence, the efficacy of neuroleptics in reducing psychotic symptoms in dementia does not always translate into improvements in daily activities and functional capacity 8 .

Atypical neuroleptics have been considered at least as effective as typical ones in controlling agitation in dementia with the advantage of reduced side effects and a more favorable EPS profile. Risperidone, a D2/HT2 blocker, is the most studied atypical antipsychotic in BPSD ${ }^{10-13}$. An open study found risperidone to be safe and effective in treating behavioral symptoms in 109 demented nursing home residents and several anecdotal reports have also been published reconfirming these findings ${ }^{12}$. To date, only two welldesigned randomized, double-blind, placebo-controlled studies with risperidone for behavioral disturbances in dementia have been published ${ }^{2,14}$. All patients included in the above mentioned studies were institutionalized with severe dementia. Despite optimal treatment of neuropsychiatric syndromes and the role of atypical neuroleptics among nursing home residents being a leading issue in the research agenda concerning elderly people ${ }^{15}$, there data do not allow direct extrapolation to outpatient samples. Further data are required to ascertain efficacy, dose range and side effect profile in this population. This knowledge could prevent unnecessary institutionalization, lessen caregiver burden and help rationalize family and public expenditures.

The present study is the first Brazilian evaluation of risperidone in dementia, as well as the first trial administering a daily dose of risperidone oral solution to an outpatient sample with agitation in dementia. Our objective in this study is to assess the efficacy and safety of risperidone oral solution in BPSD in a sample of agitated elderly out patients with dementia.

\section{METHOD}

Twenty-six elderly patients aged 60 years or more, fitting DSM-IV ${ }^{16}$ criteria for dementia with agitation and/or psychosis, were treated with increasingly higher doses of risperidone oral solution. All patients received an initial dose of $0.25 \mathrm{mg} /$ day followed by increases of $0.25 \mathrm{mg}$, up to a maximum of $3.0 \mathrm{mg}$ once daily, according to their needs. Lorazepan $2 \mathrm{mg}$ was the only medication allowed for insomnia during the first month of treatment. Biperiden $1 \mathrm{mg}$ to $2 \mathrm{mg}$ was alloved throughout the study to treat extrapyramidal symptoms (EPS).

Patients were seen weekly during the first month and at regular intervals for the proceeding four months to a total of 9 visits. Two university psychogeriatric units in Rio de Janeiro and São Paulo - Brazil, took part in the trial, both approved by the local ethics committee. All patients and their next of kin signed the informed consent to the study.

Efficacy was assessed by means of the Behavioral and Emotional Activities Manifested in Dementia (BEAM-D) ${ }^{17}$ and Clinical Global Impression (CGI) scales ${ }^{18}$, whereas for cognitive status Mini-Mental State Examination (MMSE) ${ }^{19}$ wereemployed. The Extrapyramidal Symptom Rating Scale $\left(\right.$ ESRS) ${ }^{20}$ was used to assess extrapyramidal symptoms (EPS). Cardiovascular effects where assessed by vital signs at every visits and electrocadiography (ECG) at baseline ans last visit.

Data where represented as mean and standard-deviations. Analysis of variance technique was applied to evaluate data variation over time. Pearson's correlation coefficient was calculated to measure the correlation grade between MMSE and BEAM-D Target Behaviours Scores. McNemar's test was applied to compare the proportion of patients with EPS at baseline and at final visit. The significance level was established at 0.05 and statistical analysis was performed using the SPSS ${ }^{\circ}$ statistical package.

\section{RESULTS}

26 patients ( 10 male and 16 female), with mean age of $76.35 \pm 8.63$ years, were enrolled on thestudy. Alzheimer's dementia (AD) was present in 17 patients, vascular dementia (VD) in 5, AD-VD in 6 patients. Two patients had received typical neuroleptics prior to the wash out period, and 11 patients were taking other medications such as digoxin, insulin, and antihypertensives.

Cognitive impairment was moderate or severe according to MMSE (Mean of 10.04 and standarddeviation of 7.09, range $=0-25$ ).

Tables 1 and 2 show the mean profile variation of BEAM-D Target Behaviors and BEAM-D Inferred State by dose. Comparison between BEAM-D percentage scores among doses revealed significant results for both Target Behaviors and Inferred States scores ( $p=0.05$ and $p<0.001$ respectively). For Inferred States scores, multiple comparisons among scores over a dose up to $1.25 \mathrm{mg}$ indicated that the effective daily dose fell in the range $1.00 \mathrm{mg}$ to 1.25 $\mathrm{mg}$. The difference among doses for Target Behaviours ranged between $0.25 \mathrm{mg}$ and $0.50 \mathrm{mg}$.

Extrapyramidal symptoms were present in 8 patients during initial screening and in 11 at endpoint. 
Table 1. Descriptive measures of percentage variation BEAM-D Target Behaviors scores (compared with visit 1), for each dose.

\begin{tabular}{cccccc}
\hline Dose & Mean \% & SD \% & Minimum \% & Maximum \% & $\mathrm{N}$ \\
\hline 0.25 & -5.70 & 24.44 & -70.00 & 62.85 & 25 \\
0.50 & -11.62 & 19.54 & -62.50 & 28.37 & 24 \\
0.75 & -13.49 & 18.00 & -38.09 & 18.66 & 21 \\
1.00 & -19.40 & 16.63 & -60.00 & 0.00 & 22 \\
1.25 & -13.96 & 15.33 & -43.99 & 9.53 & 15 \\
1.50 & -21.05 & 19.10 & -55.99 & 11.12 & 16 \\
1.75 & -27.78 & 17.58 & -55.99 & 0.00 & 8 \\
2.00 & -30.63 & 11.66 & -52.00 & -13.63 & 10 \\
2.25 & -40.00 & & & & 1 \\
\hline
\end{tabular}

Table 2. Descriptive measures of percentage variation of BEAM-D Inferred States scores (compared with visit 1), for each dose.

\begin{tabular}{lccccc}
\hline Dose & Mean \% & SD \% & Minimum \% & Maximum \% & $\mathrm{N}$ \\
\hline 0.25 & -5.90 & 14.14 & -44.34 & 30.00 & 25 \\
0.50 & -9.93 & 18.75 & -38.90 & 42.29 & 24 \\
0.75 & -15.20 & 18.55 & -50.01 & 27.27 & 21 \\
1.00 & -19.20 & 17.84 & -47.63 & 14.28 & 22 \\
1.25 & -23.47 & 17.23 & -41.19 & 15.38 & 15 \\
1.50 & -26.29 & 17.47 & -50.01 & 19.24 & 16 \\
1.75 & -35.40 & 13.27 & -50.01 & -10.00 & 8 \\
2.00 & -29.69 & 24.76 & -55.01 & 20.51 & 10 \\
\hline
\end{tabular}

Table 3. Patients' distribution, according to EPS measured by the ESRS at baseline and last visit.

\begin{tabular}{lccc}
\hline Baseline & Last visit & $\mathrm{N}$ & $\%$ \\
\hline No EPS & EPS & 5 & 25.0 \\
No EPS & no EPS & 8 & 40.0 \\
EPS & EPS & 6 & 30.0 \\
EPS & no EPS & 1 & 5.0 \\
Total & & 20 & 100 \\
\hline
\end{tabular}

Table 3 shows the descriptive measures of ESRS scores for each visit in those patients with positive scores. There was no significant change in the proportion of patients who presented EPS throughout the study, since only five patients with no previous symptoms presented them, all with mild intensity at endpoint. Eight patients who had not presented EPS at baseline also had no symptoms at endpoint, whereas six who had shown EPS at baseline remained unchanged and one patient improved by endpoint $(p=0.2188)$ (Table 4). No cardiovascular or clinical side effects were observed with dose increase during the four months of the trial (Table 5).

Nine patients dropped out of the study (34.6\%): 2 due to insufficient response, 4 owing to side effects and 3 for loss of follow up and consent withdrawal. All but one patient who had dropped out were considered severe/marked in CGI for agitation. All dropouts due to side effects had EPS.

\section{DISCUSSION}

Risperidone oral solution was effective in controlling BPSD, demonstrated by a mean reduction of $26 \%$ in the BEAM-D score in this sample of demented eld- 
Table 4. Descriptive measures of ESRS scores in each visit, for patients with non-null scores.

\begin{tabular}{lcccccc}
\hline & Mean & SD & Minimum & Maximum & $\mathrm{N}^{\#}$ & $\mathrm{~N}^{\alpha}$ \\
\hline Visit 1 & 6.25 & 4.87 & 2.78 & 13.89 & 8 & 26 \\
Visit 5 & 4.37 & 2.18 & 2.78 & 8.33 & 7 & 22 \\
Visit 7 & 4.72 & 3.71 & 2.78 & 13.89 & 10 & 21 \\
Visit 8 & 6.75 & 4.49 & 2.78 & 13.89 & 7 & 19 \\
Final Visit & 8.84 & 5.80 & 2.78 & 16.67 & 11 & 20 \\
\hline
\end{tabular}

\#, number of patients with non-null scores; $\notin$, number of patients with non-missing scores.

Table 5. Distribution of patients according to ECG results at first and last visits.

\begin{tabular}{lccc}
\hline First ECG & Last ECG & $\mathrm{N}$ & $\%$ \\
\hline Normal & Normal & 7 & 87.5 \\
& Abnormal & 1 & 12.5 \\
& Total & 8 & 100 \\
Abnormal & Normal & 2 & 15.4 \\
& Abnormal & 11 & 84.6 \\
& Total & 13 & 100 \\
\hline
\end{tabular}

erly outpatients after a four month period. A recent meta-analysis of randomized, double-blind controlled trials involving neuroleptics in behavioral disorders associated with dementia showed therapeutic effect to be only $26 \%$ (neuroleptic minus placebo) and showed no difference between high and low potency profiles of these drugs 9 . Two further studies, the first being a randomized, placebo controlled, double-blind design of risperidone for agitation in dementia, have produced similar results, albeit in severely demented institutionalized samples ${ }^{2,14}$. De Deyn found only $11 \%$ more patients in the risperidone group and $8 \%$ in the haloperidol group to have improved, compared to the placebo control group $^{14,15}$.

Clinicians would prefer treatment data on specific target behaviors and disturbances such as delusions, aggression, anxiety, and mood disturbances given that this is how they select drugs in clinical practice $^{15}$. Symptoms of aggression, restlessness, delusions, hallucinations and inappropriate sexual behavior seem to show a better response to medication whereas wandering and utterances respond poorly to any kind of treatment ${ }^{21,22}$.

Patients with cognitive impairment are more prone to aggressive behavior and wandering than those with milder impairment, who show more verbal agitated behaviors. However, this is observed mainly in institutions ${ }^{23}$. A recent nine year prospective study on the relationship between cognition and BPSD in a community sample of demented patients failed to show such tendencies. BPSD symptoms may appear in the beginning of the disease in its interim or final stages and can last for a period or become chronic, thus displaying no organization according to cognitive status. This study does not support the view that behavioral and psychiatric changes occur predominantly at any one stage of the illness ${ }^{24}$.

Most published data on agitation in the elderly, especially in dementia, does not specify which target symptoms have been evaluated. This often leads to unclear conclusions concerning the efficacy of the medication studied. BEAM-D is an effective tool for psychopathological description of the symptoms and their intensity, although the present study could be criticized for having used an instrument not commonly applied in similar trials, thus making it difficult to compare our results with those found in other studies. This was an outpatient sample of moderately and severely demented elderly. Taking this into consideration, it is interesting to note that the progression of cognitive decline does not necessarily correlate with a worsening of agitation when treatment is implemented. This may be important in preventing unnecessary institutionalization of patients with dementia, given that better control of insomnia, aggressiveness and psychosis may reduce caregiver burden to a more manageable level.

The likely duration of episodes of a given behavior is also relevant in that the length of treatment may be determined. Episodes of physical aggression lasted less than 10 months in $25 \%$ of $A D$ patients from a prospective study of a community sample ${ }^{24}$. Therefore, our trial has covered a time period during which no remission would be expected in the 
absence of treatment for most of the patients studied. Nevertheless, optimal duration of treatment has yet to be determined through appropriately designed controlled-studies.

The safety profile of risperidone oral solution in our study was good in respect of the emergence of EPS symptoms and cardiovascular side effects. Since only five patients without previous EPS showed mild EPS at endpoint, and eight presenting no such symptoms at baseline remained so at endpoint, we can regard risperidone as having a favorable profile concerning EPS. This data is also in agreement with that of other open label studies, a recently published retrospective study in outpatients, as well as the doubleblind risperidone trial ${ }^{2,3,25}$. De Deyn et al. ${ }^{15}$ compared risperidone and haloperidol with $0.25 \mathrm{mg}$ as a starting dose, followed by $0.25 \mathrm{mg}$ increments every four days and found riperidone to be as effective as haloperidol. Risperidone had a better side effect profile than haloperidol, compared with placebo.

Our trial also used a once a day ingestion schedule. This regimen was safe, acceptable to caregivers and effective in controlling the target symptoms. That said, the oral solution formulation may offer the additional advantage of lowering the dose required to control agitation, while allowing a 0.25 mg increment schedule, should lower strength risperidone tablets not be available, thus reducing EPS side effects.

Dropout rates are within the range observed in studies of a similar nature. Katz ${ }^{2}$ and DeDeyn ${ }^{15}$ had a $30 \%$ and $35.2 \%$ dropout rate, respectively, while meta-analytic studies showed a $4 \%$ difference in dropouts between placebo and active drug 9 . Since most of our dropouts were because of side effects combined with insufficient response, mainly in a series of more severely agitated patients, the present data are in line with the current literature.

There are several limitations to our study that should be taken into account when considering our data. We conducted an open label trial including both $A D$ and VD patients. Even though there was a washout period for previous neuroleptics and other medications which controlled agitation, it could be argued that side effects and the response profile of patients may have differed from that expected if homogenized group of patients with no previous medication were tested with risperidone. Many patients also had a series of concurrent diseases such as hypertension and diabetes, albeit under control at the time of inclusion. However, excluding patients for these medical reasons would be tantamount to excluding the "real life" circumstances that often intervene in clinical decisions. Further studies could be carried out with a more homogeneous sample of "pure" AD or VD patients. The use of BEAM-D could also be a focus of criticism as it has not commonly been used in similar studies, thus making generalization more difficult. On the other hand, BEAM-D has a complete set of definitions for each severity state and described behaviour, making it a suitable tool for defining and measuring intensity in a straightforward manner.

A considerable number of patients showed EPS at baseline. Biperiden $1 \mathrm{mg}$ to $2 \mathrm{mg}$ was the only antiparkinsonian medication used to lessen EPS, when needed. Of the seven patients who received this drug, all presented EPS at baseline. We also found it valuable to learn what might be the outcome of these patients with risperidone, although it can also be argued that the effect of risperidone alone on EPS in this sample could not be ascertained.

\section{CONCLUSION}

Risperidone was safe and effective in controlling agitation in dementia with a minimum of side effects regarding cardiovascular and extrapyramidal symptoms. The dose that showed a significant difference in controlling these symptoms varied from $1.00 \mathrm{mg}$ to $1.25 \mathrm{mg}$ once daily, providing a reduction of $26 \%$ in agitation and related states in an outpatient sample.

These results are akin to those of other open label studies with risperidone in dementia, except that ours is the first to use an oral solution formulation.

Since only two double-blind placebo controlled studies with risperidone for BPSD in institutionalized demented elderly have been published so far, there is still a need to study community and outpatient samples to ascertain the best treatment schedule, with the aim of maximizing efficacy with the least side effects possible.

\section{REFERENCES}

1. Finkel SI. Managing the behavioral and psychological signs and symptoms of dementia. Int Clin Psychopharmacol 1997;12:(Suppl 4).

2. Katz IR, Jeste DV, Mintzer JE, ClydeC, Napolitano J, Brecher M. Comparison of risperidone and placebo for psychosis and behavioral disturbances associated with dementia: a randomized, double-blind trial. J Clin Psychiatry 1999;60:107-115.

3. Herrmann N, Rivard MF, Flynn M, Ward C, Rabheru K, Campbell B. Risperidone for the treatment of behavioral disturbances in dementia: a case series. J Neuropsychiat Clin Neurosci 1998;10:220-223.

4. Cohen-Mansfield J, Marx MS, Werner P. Agitation in elderly persons: an integrative report of findings in a nursing home. Int Psychogeriatr 1992;4(Suppl 2):221-240.

5. Tariot PN, Blazina L. The psychopathology of dementia. In Moriss JC (ed). Handbook of dementing illnesses. New York: Marcel Dekker, 1994:461-475. 
6. Tariot PN. Treatment of agitation in dementia. J Clin Psychiatry 1999;60(Suppl 8): 11-20.

7. American Psychiatric Association. Work Group on Alzheimer's Disease and Related Disorders. Practice guideline for the treatment of paitnets with Alzheimer's disease and other dementias of lale life. Am J Psychiatry 1997;154(Suppl 5):1-39.

8. Rummans TA, Lauterbach EC, Coffey CE, et al. Pharmacologic efficacy in neuropsychiatry: a review of placebo-controlled treatment trials. J Neuropsychiat Clin Neurosci 1999;11:176-189.

9. Lanctôt KL, Best TS, Mittmann N, et al. Efficacy and safety of neuroleptics in behavioral disorders associated with dementia. J Clin Psychiatry 1998;59:550-561.

10. Madhusoodanan S, Brenner R, A raujo L, et al. Efficacy of risperidone treatment for psychoses associated with schizophrenia, bipolar disorder, or senile dementia in 11 geriatric patients: a case series. J Clin Psychiatry 1995;56:514-518.

11. Jeanblanc W, Davis YB. Risperidone for treating dementia-related aggression. Am J Psychiatry 1995;152:1239.

12. Goldberg RJ, Goldberg J. Risperidone for dementia-related disturbed behavior in nursing home residents: a clinical e experience. Int Psychogeriat 1997;9:65-68.

13. Schneider LS. Pharmacologic management of psychosis in dementia. J Clin Psychiatry 1999; 60(Suppl 8):54-60.

14. De Deyn PP, Rabberu K, Rasmussen A, et al. A randomized trial of risperidone, placebo, and haloperidol for behavioral symptoms of dementia. Neurology 1999;53:946-955.
15. Cummings JL, Knopman D. Advances in the treatment of behavioral disturbances in Alzheimer's disease. Neurology 1999; 53: 899-901.

16. American Psychiatric Association. Diagnostic and statistical manual of mental disorders. 4.Ed. Washington: APA, 1994.

17. Sinha D, Zamlan FP, Nelson S, et al. A new scale for assessing behavioral agitation in dementia. Psychiat Res 1992;41:73-88.

18. Guy W. ECDEU assessment manual for psychopharmacology. Rockville: National Institute of Mental Health, Education, and Welfare, 1976:76-338.

19. Folstein MF, Folstein SE, McHugh PR. "Mini-mental state": a practical method for grading the cognitive state of patients for the clinician. J Psychiat Res 1975;12:189-198.

20. Chouinard G, Ross-Canard A, Annable L, Jones BD. The extrapyramidal symptom rating scale. Can J Neurol Sci 1980;7:233.

21. Cohen-Mansfield J, Billig N. A gitated behaviors in the elderly: a conceptual review. J Am Geriatr Soc 1986;34:711-721.

22. Zayas EM, Grossberg GT. Treating the agitated Alzheimer patient. J Clin Psychiatry 1996; (Suppl 7):46-51.

23. Cohen-Mansfield J, Marx MS, Rosental AS. Dementia and agitation in nursing home residents: how arethey related? Psychol Aging 1990; 5:3-8.

24. Hope T, Keene J, Fairburn CG, Jacoby R, MCShane R. Natural history of behavioral changes and psychiatric symptoms in Alzheimer's disease. A longitudinal study. Br J Psychiatry 1999;174:33-44.

25. Irizarry MC, Ghaemi SN, LeeCherry E, et al. Risperidone treatment of behavioral disturbances in outpatients with dementia. J Neurpsychiat Clin Neurosci 1999;11:336-342. 